\title{
Management Factors Associated with Impaired Locomotion in Dairy Cows in England and Wales
}

\author{
Z. E. Barker, ${ }^{\star} \dagger^{1}$ J. R. Amory, ${ }^{\star} \ddagger$ J. L. Wright, ${ }^{*}$ R. W. Blowey, $\S$ and L. E. Green ${ }^{\star}$ \\ ${ }^{*}$ Ecology \& Epidemiology Group, Department of Biological Sciences, University of Warwick, CV4 7AL, United Kingdom \\ †University of Bristol, Division of Animal Health and Husbandry, Department of Clinical Veterinary Science, Langford House, \\ Langford, Bristol BS40 5DU, United Kingdom \\ $\ddagger$ Current address, Centre for Equine and Animal Science, Writtle College, Chelmsford, Essex, CM1 3RR, United Kingdom \\ §Wood Veterinary Group, Gloucester, GL2 4NB, United Kingdom
}

\section{ABSTRACT}

Forty-nine farms in England and Wales were visited on 4 occasions between February 2003 and March 2004. A total of 21,693 scores of locomotion were assigned to 7,722 cattle. Locomotion was assessed on a 3-point scale by observing the posture of a cow's back while standing and walking ( $1=$ sound, $2=$ not sound, $3=$ lame). Data on measurable factors potentially associated with locomotion were collected from all farms using direct observations of the farm environment and a comprehensive farmer interview. The mean herd locomotion score was $1.77 \pm 0.02$. There was no significant difference in mean herd locomotion scores between 5 herds housed in straw yards $(1.72 \pm 0.02)$ and 44 herds housed in free stalls $(1.78 \pm 0.02)$, possibly because of lack of power. A GLM was produced using data from the 44 herds housed in free stalls, with the mean farm locomotion score of all cows examined on all 4 visits as the outcome variable. Factors associated with an elevated locomotion score were dry cows kept in straw yards compared with free stalls (increase in locomotion score $=0.06 \pm 0.03$ ), pregnant heifers kept with milking cows in winter compared with being kept with dry cows (increase in locomotion score $=0.09 \pm 0.03$ ), aisle widths of $<3 \mathrm{~m}$ compared with widths of $\geq 3 \mathrm{~m}$ (increase in locomotion score $=0.06 \pm$ 0.02 ), a curb height of $\leq 15 \mathrm{~cm}$ compared with a height of $>15 \mathrm{~cm}$ (increase in locomotion score $=0.07 \pm 0.03$ ), routine trimming of hooves of all cows by a hoof trimmer or by the farmer compared with no routine hoof trimming (increase in locomotion score $=0.18 \pm 0.04$ and $0.13 \pm 0.03$ respectively), feeding corn silage to milking cows compared with feeding other forage types (increase in locomotion score $=0.10 \pm 0.03$ ), and the use of automatic scrapers in the free-stall barn compared with tractor scrapers (increase in locomotion score $=$

Received March 24, 2006.

Accepted March 5, 2007.

${ }^{1}$ Corresponding author: zoe.barker@bristol.ac.uk
$0.10 \pm 0.03)$. These variables were correlated with many other management variables. The use of automatic scrapers was correlated with the use of sawdust on rubber mats in free stalls. Curb height was negatively correlated with increasing distance of the neck rail from the front (head end) of the free stall. These putative risk factors support the hypothesis that locomotion score is linked to management factors; in particular, the combination of sawdust on rubber mats with automatic scrapers was associated with elevated locomotion scores.

Key words: lameness, locomotion score, risk factor, multivariable modeling

\section{INTRODUCTION}

Lameness in dairy cattle reduces productive life (Seegers et al., 1998), infringes on welfare (O'Callaghan et al., 2003), and causes direct economic costs through treatment (Kossaibati and Esslemont, 1997) and indirect economic costs through lost milk production (Green et al., 2002). During the winter housing period, cows are exposed to a number of potential risks for lameness. The base and bedding materials used in cow free stalls vary across farms, and it is not clear which, if any, of the available surfaces are best for the health of legs and claws. Wechsler et al. (2000) reported a significantly higher incidence of leg injuries on the tarsus (hock) in cows housed in free stalls with mats compared with those on free stalls bedded with straw. Given a choice, cows preferred free stalls deeply bedded with sawdust or sand to cow mattresses (Tucker et al., 2003). Improved lying times were reported for straw yards when compared with free stalls (Singh et al., 1993a), and Singh et al. (1993b) reported that increased standing times were related to reduced locomotion and increased sole lesion scores. Faull et al. (1996) reported increased lameness (locomotion scores) in 37 herds associated with limited "borrowing" space at the front and side of free stalls, low side rails, curb heights of $>16 \mathrm{~cm}$, low quantities of bedding in stalls, and smooth walking surfaces in the free-stall barn. 
The floor surfaces outside the lying area in the winter housing environment may be important for lameness control. Somers et al. (2005) reported an increased risk of digital dermatitis for cows housed on solid concrete floors, compared with those on slatted floors with and without automatic scrapers. These authors reported that cows with restricted or zero grazing had an increased risk of digital dermatitis; this might be because these cattle have a high stocking density and a high exposure to disease-causing organisms in slurry.

Hoof-trimming procedures were investigated with respect to the spread of digital dermatitis. Wells et al. (1999) reported a decreased risk of digital dermatitis when hoof trimming equipment was washed between cows and an increased risk when farmers used a hoof trimmer that trimmed cattle on other farms.

Finally, previous reports indicate that high-starch, low-fiber diets result in significantly higher incidences of laminitis (inflammation of the corium), sole ulcer, white line lesions, and heel erosions (Livesey and Fleming, 1984; Livesey et al., 1998; Webster, 2001). The first priority for farmers and veterinarians is to reduce the number of lame cows before reducing lesions on hooves that are not apparently causing lameness. Consequently, this paper focuses on risks for increased mean locomotion score; that is, a high prevalence of lameness from any cause.

A number of techniques have been used to score locomotion. Sprecher et al. (1997) reported that the assessment of back posture could be used to distinguish normal, mildly lame, and moderately lame cattle (scores 1 to 3 ) and that moderate (score 3) and severely lame cattle (scores 4 and 5) could be distinguished by foot placement. Amory et al. (2006) used a modification of the method of Sprecher et al. (1997) with 3 groups for locomotion [normal or sound (1), unsound (2), and lame (3 to 5)] to study 19 dairy herds in the Netherlands. This system uses back posture primarily to define locomotion. The current report uses the same scoring system and presents a prospective study of management factors associated with impaired locomotion on 49 dairy herds in England and Wales.

\section{MATERIALS AND METHODS}

\section{Data Collection}

Fifty-two dairy farmers in England and Wales, sourced from a database of farmers who had participated in a study by Peeler et al. (2000), were recruited into this study. The farmers were contacted by mail, and those that expressed an interest and attended a training evening on hoof lesion recognition were enrolled in the study. The farms were visited 4 times between February 2003 and March 2004 by one re- searcher (ZB) and 1 of 3 colleagues. Visit 1 took place in late winter/spring. These visits were during late housing/early grazing. Visit 2 took place during the summer and all cattle were at pasture. Visit 3 took place in fall/winter soon after the cows were housed. Finally, visit 4 took place at the end of the winter housing period. The mean time between visits to each farm was 108 (56 to 199) d.

A 3-point locomotion scoring system (Amory et al., 2006) was used at each of the 4 visits to assess locomotion in cows by observing the presence or absence of an arched back when walking and when standing (Table 1). Two recorders were present at 179/201 (89\%) of the farm visits, with the remaining locomotion scoring sessions being completed by one researcher (ZB). Where 2 recorders were present at a farm visit, any locomotion scores that were not immediately apparent to the first recorder were discussed with the second and an agreed score was recorded. Where possible, all cows were scored standing and walking in a straight line on a firm, flat walking surface (i.e., in a yard or field) uninterrupted by other cows or stock people and avoiding sharp turns.

Direct observations (Table 2) of potential risk factors for lameness in the environment of the cow were recorded at one (unchanging risks) or more (changing risks) of the 4 visits. Bedding depth and cleanliness were scored at visits 1,3 , and 4 when cows were housed, using a 3-point scale (Table 1).

A farmer interview was used to gather data on farm management in the previous 24 mo. The data gathered included general farm information (herd type, milk yield, building types and use, grazing area and method of grazing, track surfaces and construction, housing, and turnout dates), nutritional management (forage, concentrate and supplement inclusion), cattle breeding and replacement management (calving period, breeding age, and selection characteristics), heifer and dry cow management (where housed and with whom, transition management, and free-stall training), and lameness treatment and control (footbath type, frequency and solution used, trimming frequency, use of a professional hoof trimmer, and method of recording lameness).

All farmers fed their cattle a conserved forage ration with a compound feed or blend during the winter housing period. The ration was presented as a TMR or as forage with additional concentrate fed in or out of parlor. All cows were turned out to pasture during the summer grazing period. Lame cows were treated using the usual farm management practices; in most cases, this was treatment by the farmer. 
Table 1. Observations of locomotion scores and bedding at farm visits in England and Wales

\begin{tabular}{|c|c|c|c|}
\hline Score system & Score 1 & Score 2 & Score 3 \\
\hline \multirow[t]{2}{*}{ Locomotion score ${ }^{1}$} & Flat back when standing & Flat back when standing & Arched back when standing \\
\hline & Flat back when walking & Arched back walking & Arched back when walking \\
\hline Bedding cleanliness $^{2}$ & Clean and dry & Lightly soiled but dry & Heavily soiled and wet \\
\hline Bedding depth ${ }^{2}$ & Deep and even & Uneven and patchy & Little or no bedding \\
\hline
\end{tabular}

\section{Data Management and Analysis}

A Microsoft Access (2002, Microsoft, Redmond, WA) database was set up for data entry. The data were checked for data entry errors and missing values and amended using the paper records or by a follow-up call to the farmer.

For each farm, the sum of all locomotion scores from all 4 visits (Figure 1A) was divided by the total number of locomotion score recordings to estimate the mean farm locomotion score $(1.77 \pm 0.02)$; this was normally distributed (Figure 1B) and was used as the outcome variable for all models. Bedding cleanliness, bedding depth, and fecal score were measured at all visits, and mean scores were calculated as for mean locomotion score. Mean bedding depth, bedding cleanliness, and fecal consistency scores were calculated for both milking and dry cows using measurements taken at visits 3 and 4 when all cows were housed and fed winter rations.
Continuous variables were checked for linearity with the outcome variable and nonlinear variables were categorized. Categorical variables with $<5$ observations in the area of interest were excluded from the analysis. All suitable variables were tested, one at a time, in a univariable linear regression model with mean farm locomotion score as the outcome. All explanatory variables with a statistical association of $P<0.2$ were tested using backward elimination in submodels of the winter housing environment, lactating cow nutrition, dry cow management, heifer management, cow health and milk quality, free-stall dimensions and damage, and summer pastures and laneways. Variables significant at $P<0.05$ were retained in the submodels. These variables were tested in a final model developed as described above, with the 5 herds housed on straw yards excluded. All nonsignificant variables were reentered into the final model one by one to investigate residual confounding,

Table 2. Summary of observations of farms in England and Wales made during summer and winter housing conditions

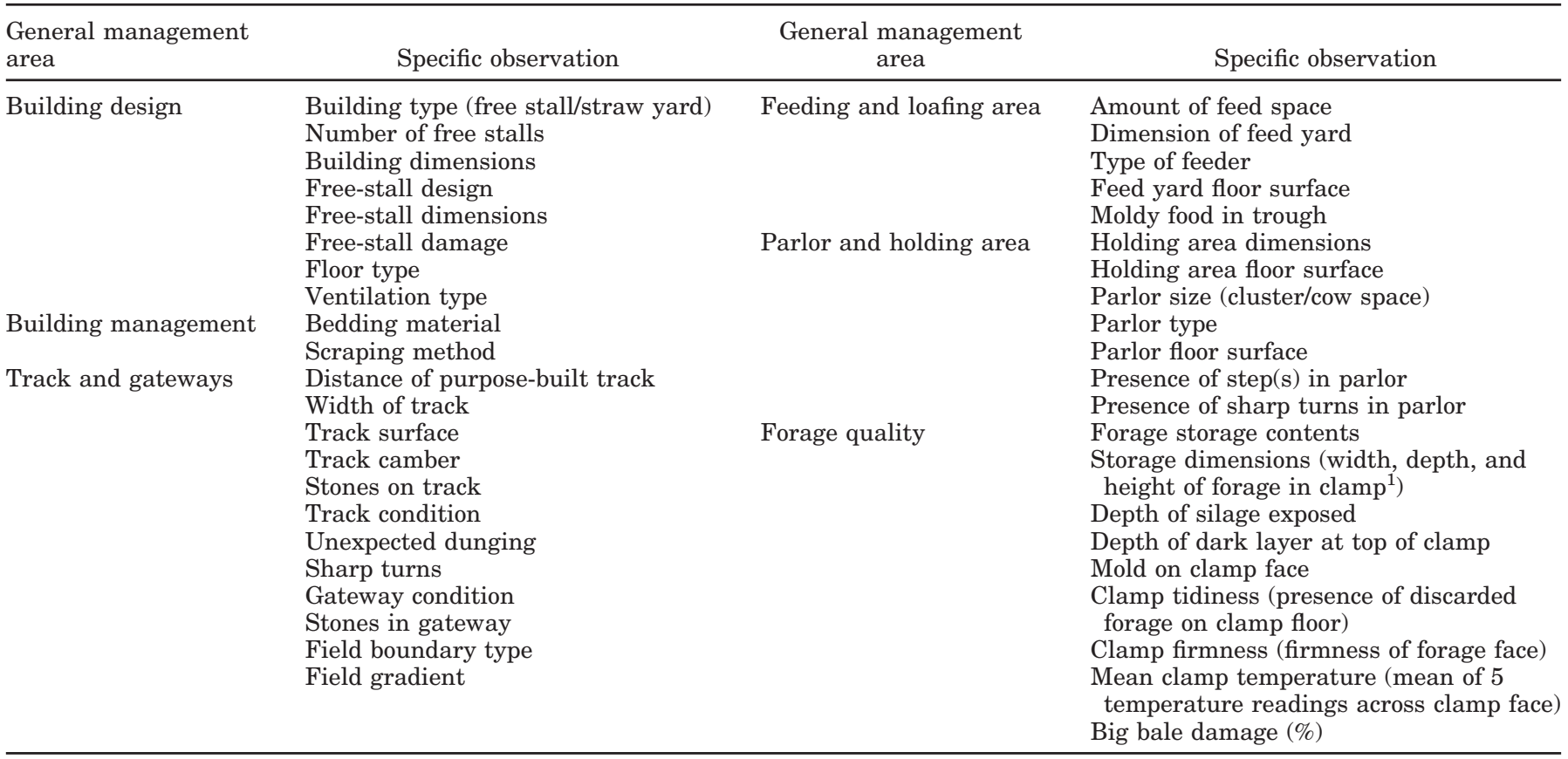

\footnotetext{
${ }^{1}$ Polyethylene-covered storage area.
} 

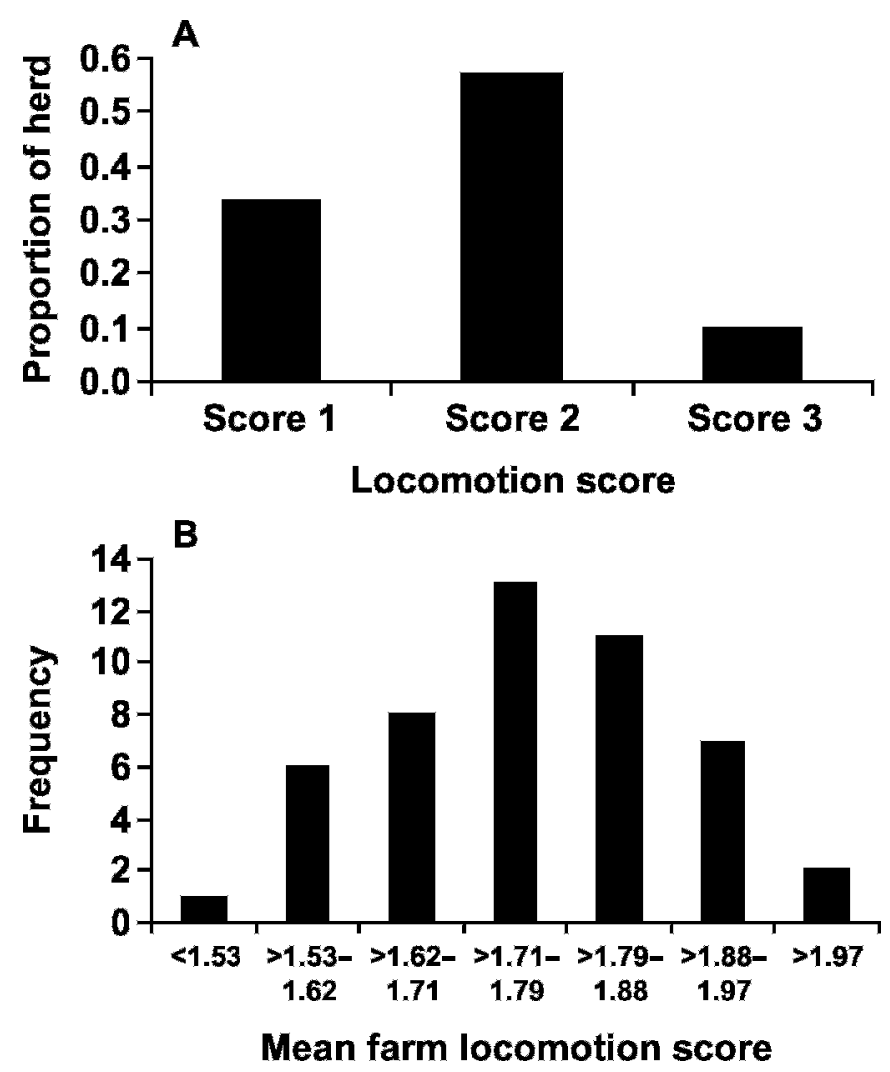

Figure 1. A) Proportion locomotion scores 1 to 3 recorded by researchers across 4 visits to 49 dairy farms in England and Wales. B) Mean farm locomotion scores for 49 farms in England and Wales.

and any variable significant at $P<0.05$ was left in the model. Finally, mean herd size and average annual milk yield were added to the model to investigate confounding effects of these variables. Model fit was assessed. Pearson correlation coefficients between explanatory variables were estimated. All statistical analyses were carried out using SPlus Professional Edition (Version 6.2, 2003, Insightful Corp., Basingstoke, Hampshire, UK).

\section{RESULTS}

\section{General Farm Information}

Forty-nine of the 52 farmers remained in the study for the entire data collection period. The mean herd size was $109 \pm 10$ (range 38 to 421 ). The mean milk yield was $7,830 \pm 183$ (range 5,000 to 10,200 ) kg/cow per year. The majority of herds consisted of entirely Holstein cattle, Holstein-Friesian cattle, or both ( $\mathrm{n}=$ 42); the rest had a small proportion of other breeds or crossbreeds ( $\mathrm{n}=7)$, including Jerseys, Ayrshires, Brown Swiss, and Meuse Rhine Issels. The overall mean farm locomotion score was $1.77 \pm 0.02$ (range 1.53 to 2.05).
The crude locomotion scores by farm management and housing are listed in Table 3 . There was no significant difference $(P=0.27)$ between mean locomotion score in herds kept on straw yards $(1.72 \pm 0.02)$ and those housed in cubicles $(1.78 \pm 0.02)$.

\section{Multivariable Linear Regression Analysis}

The 5 farms with straw yard housing were excluded from the multivariable model to allow inclusion of variables related to free-stall housing. Seven variables were significantly associated with an elevated mean locomotion score in the final GLM (Table 4). These were housing dry cows on straw yards compared with free stalls, mixing pregnant heifers with the milking cows in winter before calving compared with mixing pregnant heifers housed with dry cows, passageway widths of $<3 \mathrm{~m}$, compared with widths of $\geq 3 \mathrm{~m}$, a curb height of $\leq 15 \mathrm{~cm}$ compared with a height of $>15 \mathrm{~cm}$, routine trimming of hooves of all cows by a hoof trimmer or by the farmer compared with no routine hoof trimming, feeding corn silage to milking cows, and the use of automatic scrapers in the free-stall housing compared with tractor scrapers.

\section{Correlations}

The use of sawdust on top of mats or mattresses was positively correlated with automatic scrapers $(\mathrm{r}=0.34$, $P<0.05)$ and negatively correlated $(\mathrm{r}=-0.48, P<0.01)$ with tractor scraping. Both using automatic scrapers and using sawdust on mats were associated with an elevated mean locomotion score in the model, but because of the high degree of correlation between the variables, only one remained in the final model. Tractor scraping and automatic scrapers were significantly $(P$ $<0.05$ ) associated with the presence of a brisket board ( $\mathrm{r}=-0.41, \mathrm{r}=0.45$, respectively), the distance of the neck rail from the head end of the cubicle $(r=-0.43$, $\mathrm{r}=0.35$, respectively), and the number of cows per regular milker $(\mathrm{r}=-0.40, \mathrm{r}=0.39$ respectively). The curb height was negatively correlated with the distance of the neck rail from the head end of the cubicle ( $\mathrm{r}=$ -0.28). Feeding corn silage was significantly negatively correlated with feeding concentrate in the parlor $(\mathrm{r}=$ $-0.28)$ and not feeding a transition ration $(r=-0.37)$, and was positively correlated with the number of cows per regular parlor worker $(r=0.50)$ and with sawdust on mats $(\mathrm{r}=0.27)$. Routine claw trimming of all cows by the farmer was positively correlated with free stalls with floors of sawdust on mats $(r=0.30)$, whereas routine hoof trimming of some cows by the farmer was negatively correlated with the same $(r=-0.28)$. Routine foot trimming by the farmer of some or all cows was 
Table 3. Number and percentage of exposure, and difference in mean locomotion score for management and housing variables for 49 farms in England and Wales

\begin{tabular}{|c|c|c|c|c|}
\hline Exposure & Item & Number $(\%)$ & $\begin{array}{l}\text { Mean locomotion } \\
\text { score } \pm \mathrm{SE}\end{array}$ & $P$ \\
\hline Herd type & $\begin{array}{l}\text { Conventional } \\
\text { Organic }\end{array}$ & $\begin{aligned} 45 & (92) \\
4 & (8)\end{aligned}$ & $\begin{array}{l}1.78 \pm 0.02 \\
1.64 \pm 0.01\end{array}$ & 0.02 \\
\hline Herd size (per 100 cows $)^{1}$ & Intercept $=1.67$ & & $0.09 \pm 0.02^{2}$ & $<0.01$ \\
\hline Nutrition & $\begin{array}{l}\text { Milking cows not fed corn silage } \\
\text { Milking cows fed corn silage }\end{array}$ & $\begin{array}{l}32(65) \\
17(35)\end{array}$ & $\begin{array}{l}1.73 \pm 0.02 \\
1.84 \pm 0.01\end{array}$ & $<0.01$ \\
\hline Trimming & $\begin{array}{l}\text { No routine trimming } \\
\text { Some cows trimmed by stockman } \\
\text { All cows trimmed by stockman } \\
\text { All cows trimmed by hoof trimmer }\end{array}$ & $\begin{aligned} 13 & (27) \\
7 & (14) \\
20 & (41) \\
9 & (18)\end{aligned}$ & $\begin{array}{l}1.71 \pm 0.01 \\
1.73 \pm 0.02 \\
1.80 \pm 0.02 \\
1.84 \pm 0.02\end{array}$ & $\begin{array}{l}0.67 \\
0.01 \\
0.02\end{array}$ \\
\hline Foot bathing & $\begin{array}{l}\text { No footbath used } \\
\text { Regular foot bathing }\end{array}$ & $\begin{array}{l}18(37) \\
31(63)\end{array}$ & $\begin{array}{l}1.77 \pm 0.02 \\
1.77 \pm 0.02\end{array}$ & 0.91 \\
\hline Scraping method & $\begin{array}{l}\text { Automatic scrapers } \\
\text { Tractor scraper } \\
\text { Slatted floors (no scraping) }\end{array}$ & $\begin{aligned} 8 & (18) \\
34 & (77) \\
2 & (5)\end{aligned}$ & $\begin{array}{l}1.88 \pm 0.02 \\
1.75 \pm 0.02 \\
1.76 \pm 0.02\end{array}$ & $\begin{array}{c}<0.01 \\
0.15\end{array}$ \\
\hline
\end{tabular}

${ }^{1}$ All variables were categorical except herd size, which was continuous.

${ }^{2}$ Represents the increase in mean locomotion score associated with every increase in herd size of 100 cows.

Table 4. Final model of factors associated with mean farm locomotion score for 44 free stall housed milking herds in England and Wales

\begin{tabular}{lrrrrrr}
\hline & & & & & Lower & Upper \\
Exposure & Number & Coefficient $^{1}$ & \multicolumn{1}{c}{$\mathrm{SE}$} & $P$ & $95 \% \mathrm{CI}^{2}$ & $95 \%$ CI \\
\hline Intercept & & 1.65 & 0.04 & $<0.01$ & 1.57 & 1.74 \\
Cows in free stalls when dry and in milk & 33 & & & & & \\
Cow in straw yards when dry & 9 & 0.06 & 0.03 & 0.04 & 0.01 & 0.12 \\
Unknown & 2 & -0.01 & 0.08 & 0.90 & -0.17 & 0.15 \\
Maximum passage width $\geq 3 \mathrm{~m}$ & 24 & & & & & \\
Maximum passage width $\leq 3 \mathrm{~m}$ & 20 & 0.06 & 0.02 & 0.02 & 0.01 & 0.12 \\
Automatic scrapers & 8 & & & & & \\
Slatted floor (no scraping) & 2 & -0.02 & 0.06 & 0.72 & -0.14 & 0.09 \\
Tractor scraper & 34 & -0.10 & 0.03 & $<0.01$ & -0.16 & -0.04 \\
Pregnant heifers housed with dry cows & 31 & & & & & \\
Pregnant heifers housed with milking cows & 12 & 0.09 & 0.03 & $<0.01$ & 0.03 & 0.15 \\
Pregnant heifers only & 1 & -0.14 & 0.12 & 0.25 & -0.37 & 0.09 \\
No routine trimming & 11 & & & & & \\
Farmer trims some cows & 7 & 0.03 & 0.04 & 0.51 & -0.05 & 0.11 \\
Hoof trimmer trims all cows & 9 & 0.18 & 0.04 & $<0.01$ & 0.11 & 0.25 \\
Farmer trims all cows & 17 & 0.13 & 0.03 & $<0.01$ & 0.06 & 0.19 \\
Corn silage not fed & 29 & & & & & \\
Corn silage fed & 15 & 0.10 & 0.03 & $<0.01$ & 0.04 & 0.15 \\
Curb height $>15$ cm & 31 & & & & & \\
Curb height $\leq 15$ cm & 13 & 0.07 & 0.03 & 0.03 & 0.01 & 0.12 \\
\hline
\end{tabular}

${ }^{1}$ Coefficient $=$ estimated mean change in locomotion score by variable, baseline 1.65.

${ }^{2} \mathrm{CI}=$ confidence interval. 
positively correlated with milk yield $(r=0.28)$. Routine trimming of hooves by a professional hoof trimmer was not correlated with milk yield but was positively correlated with herd size $(r=0.29)$. Automatic scrapers in the free-stall housing and feeding corn silage were positively correlated with herd size $(r=0.52)$.

\section{DISCUSSION}

Locomotion scores provide an estimate of the prevalence of lameness in a herd. Scoring many cattle on many farms and correlating this with management practices can assist our understanding of impaired locomotion and provides the opportunity to generate hypotheses for improved locomotion whatever the etiology of specific lesions.

The 3-point scoring system used (Amory et al., 2006) placed cattle in 1 of 3 scores with relative ease. A small fraction of cattle, less than $1 \%$, required more consideration. This occurred when cattle had unusual conformation with an arched back at the withers, dipped loins, or both. For these cattle, the transition between walking and standing was observed to identify changes in the posture of the lower back. In some very rare cases, cows were observed standing with a flat back but were not bearing weight on one limb, and therefore were given a locomotion score of 3 . Locomotion score varies by floor surface (Phillips and Morris, 2001), so all cattle were scored on concrete both when housed and while at pasture where possible; however, where this was not possible, cattle were scored at pasture during the summer grazing period. Inevitably in large observational studies, there will be a misclassification of scores, which may lower the precision of the model estimates, but we aimed to minimize this by scoring herds on 4 occasions with the 3 -score definitions for locomotion (Table 1). The percentage of locomotion score 3 cattle (Figure 1A), together with the number of observations, indicated that a binomial outcome model categorized at score 3 would approximate a continuous model; binomial models are less robust than Gaussian models because they are approximations. Consequently, a continuous outcome model was used. The distribution of mean locomotion scores (Figure 1B) and the model fit (Figure 2 ) indicate that this was a statistically robust decision.

The final model, together with the correlations, takes into account the complex relationships between the large numbers of on-farm factors. Factors correlated with those in the main model, but less statistically associated with the mean locomotion score, provided valuable information about how the factors related to each other.

One variable associated with impaired locomotion in the analysis was the use of automatic scrapers to clean the free-stall barn compared with using a tractor scraper. Automatic scrapers can improve hygiene in the free-stall barn because of frequent scraping, but can make cows dirtier as the wave of slurry that forms coats the claws and possibly the lower legs of cattle. This may be associated with impaired locomotion. In addition, the scraper movement may result in cows moving rapidly to avoid its path. Stefanowska et al. (2001) reported that $94 \%$ of stumble incidents observed in 2 different housing systems, both with automatic scrapers, occurred as a result of contact with the scrapers. Automatic scrapers may cause further disruption during feeding times because cows, in particular those with low social ranking, may be displaced from their position at the feed barrier.

Automatic scrapers were highly correlated with freestall design and with free-stall floors of sawdust on mats. Such lying surfaces were associated with lower lying times (Tucker et al., 2003), and decreased lying times were associated with a greater prevalence of hoof lesions and tarsal damage (Wechsler et al., 2000). Automatic scrapers were confounded with the presence of a brisket board and the distance of the neck rail from the front of the free stall. The presence of brisket boards and the position of the neck rail can help prevent animals from lying or standing too far forward in the free stall and so encourage dunging into the passageway in the path of the automatic scrapers. Nevertheless, the position can be inappropriate and reduce free-stall comfort, and therefore reduce lying times. The brisket boards may be positioned to secure cow mats (on which the predominant bedding type is sawdust) and so might not be in the best position for the cow.

Curb heights of $\leq 15 \mathrm{~cm}$ were associated with increased mean locomotion scores. In contrast to this, Faull et al. (1996) reported that curb heights of $>16$ $\mathrm{cm}$ were associated with increased lameness. In the current study, low curb heights were correlated with neck rails further from the front (head end) of the free stall, and there was a trend for farms with lower curb heights to use brisket boards. Curb height may be a marker for other aspects of free-stall design. It was correlated with automatic scrapers and so may be linked to poor hygiene.

The final variable associated with housing design was that herds housed in free-stall houses where the passageway widths were $\geq 3 \mathrm{~m}$, compared with $<3 \mathrm{~m}$, had a decreased mean locomotion score. Wider passageways might allow good flow of cattle around the house and so assist cow flow and integration of new herd members; they also provide a larger floor area and so reduce the accumulation of slurry, which might reduce the risk of digital dermatitis. Further investigation of cattle in these systems by studying their walking and standing 


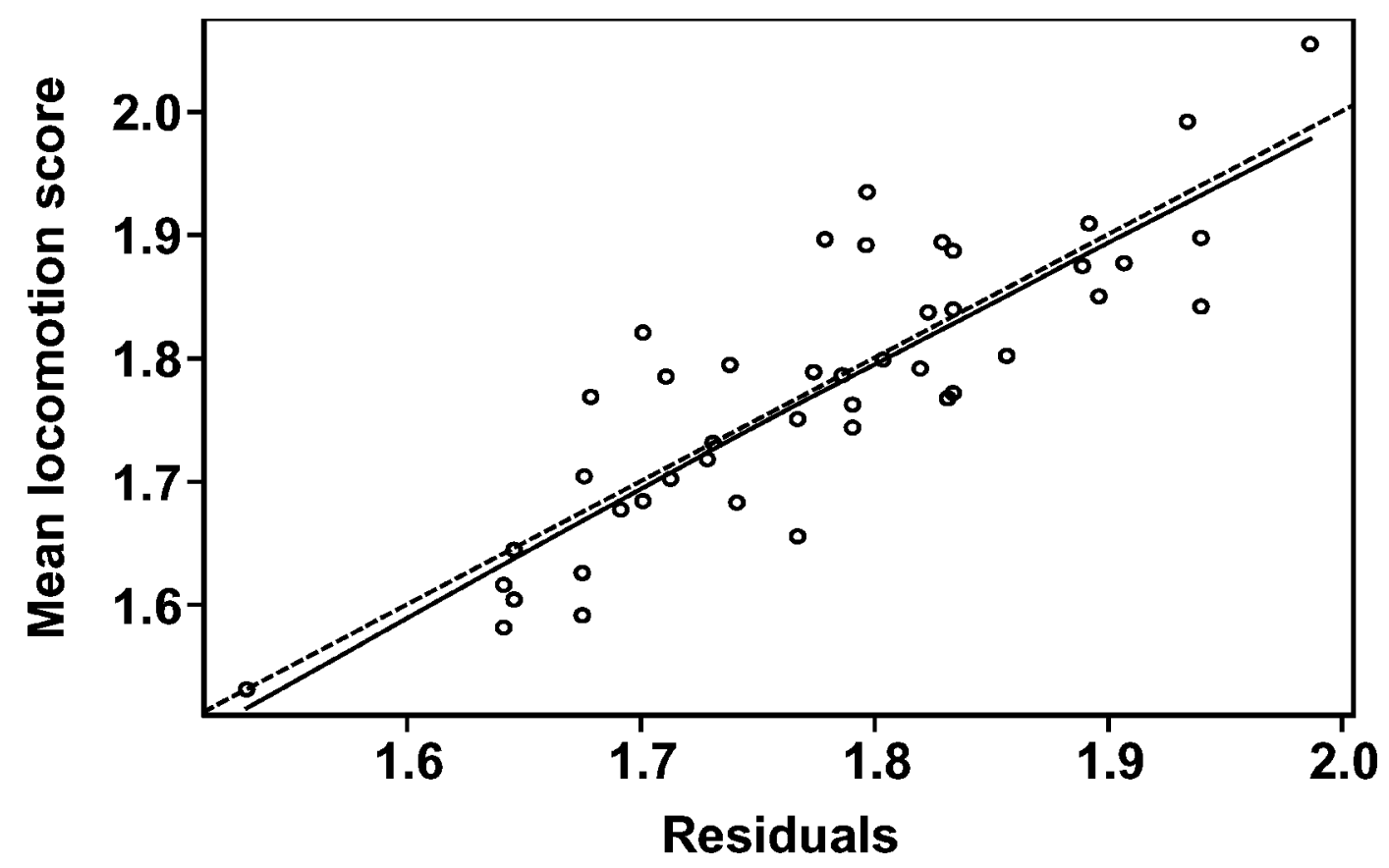

Figure 2. Plot of residuals from a multivariable model describing risk factors for increased locomotion score vs. fitted mean locomotion score for 44 farms in England and Wales, indicating a reasonable model fit. The dotted line indicates the fit of the model; the solid line indicates the confidence limit of the fitted model.

behavior around automatic scrapers, curbs, and passageways and their lying behavior with sawdust and mat free-stall floors, brisket boards, and head rails is clearly required to investigate these complex associations.

Vermunt and Greenough (1996) reported increased toe length in heifers housed in an outdoor dry lot with a straw-bedded lying area, compared with heifers housed in free stalls with slatted floors. Soft floor surfaces slow horn growth and wear and alter hoof conformation; the rate of wear then increases when cows are kept on hard floors. Nonetheless, the rate of horn production does not initially match the rate of wear and the sole horn becomes thin, with an increased risk of sole ulcers. In the current study, herds with dry cows housed in straw yards were associated with impaired locomotion when compared with herds in which dry cows were housed in free stalls. Such cattle experience the change from soft to hard floors as they enter the free stalls at calving, and consequently may be more prone to sole lesions. In addition, lactating cows have less time to lie down compared with dry cows, and this may cause further wear of the distal horn (Singh et al., 1993a).

There was a small increase in the mean locomotion score associated with pregnant heifers housed with milking cows in the winter compared with heifers housed with dry cows. A possible explanation for this is that pregnant heifers are likely to be below milking cows in the social hierarchy. Therefore, they may make evasive maneuvers that may predispose them to white line disease (Chesterton, 2004). They may have long standing times competing for food and space, and possibly in the parlor. These behaviors may predispose them to horn damage and outweigh the advantages of integration into the herd. In addition, any stability in the social hierarchy brought about by introducing pregnant heifers before calving will be disrupted when they are removed to the calving pen and then returned to the herd after calving (Kondo and Hurnik, 1990); the results from this study suggest that this management practice should be questioned.

Routine hoof trimming of all cows, either by a professional hoof trimmer or by the farmer, was associated with an increased mean herd locomotion score compared with those herds in which no routine trimming took place. This suggests that routine trimming of all cows once per year may not be an effective method of controlling the prevalence of lameness. This may be because lame and unsound cows were left untreated until the next visit by the professional trimmer. Another possibility is that inadequate hygiene of hooftrimming equipment or poor foot-trimming technique after led to lameness after trimming (Wells et al., 1999).

The feeding of corn silage was associated with an increase in the mean locomotion score. Feeding corn 
silage was associated with rumen acidosis and disruption of horn production caused by inflammation within the hoof (Mülling et al., 1999). Herds feeding corn silage will be higher yielding, further increasing the risk of lameness. Faye and Lescourret (1989) demonstrated that the presence of laminitis is associated with long periods of feeding corn silage.

Previous studies have suggested that herd size and yield are related to lameness (Alban, 1995). Such an association may not in itself be useful because farmers will rarely reduce herd size or yield. On the other hand, these variables may be correlates for various farm management practices. In the current study, large herd size was associated with feeding corn silage, automatic scraping in the free stalls, sawdust and mat free-stall floors, and using a professional hoof trimmer. These factors, rather than yield or herd size, may be changed to test whether they are causally related to impaired locomotion.

\section{CONCLUSIONS}

Impaired locomotion was associated with passage aisles of $<3 \mathrm{~m}$, automatic scrapers, low curb heights, sawdust on mats, feeding corn silage, housing dry cows in straw yards, mixing pregnant heifers with milking cows, and routinely trimming all hooves. This provides valuable information on which to base intervention studies.

\section{ACKNOWLEDGMENTS}

This study is part of a European Union-funded framework 5 project (OLRT-2001-00969), "A Multidisciplinary Approach to the Reduction in Lameness and Improvement in Dairy Cow Welfare in the European Community, Lamecow." The data collected and locomotion scores used were developed through contributions from all those who attended the first meeting of the European Union Lamecow project in Aberdeen, December 2002. We particularly thank Thomas Manske for his input into this discussion. The authors thank all the farmers for their valuable time and assistance.

\section{REFERENCES}

Alban, L. 1995. Lameness in Danish dairy cows: Frequency and possible risk factors. Prev. Vet. Med. 22:213-225.

Amory, J. R., P. Kloosterman, Z. E. Barker, J. L. Wright, R. W. Blowey, and L. E. Green. 2006. Risk factors for reduced locomotion in dairy cattle on nineteen farms in The Netherlands. J. Dairy Sci. 89:1509-1515.

Chesterton, R. N. 2004. Linking farm physical conditions, herd management and cow behaviour to the distribution of foot lesions causing lameness in pasture-fed dairy cattle in New Zealand. Pages 200-202 in Proc. 13th Int. Symp. \& 5th Conf. Lameness in
Ruminants, Maribor, Slovenia. B. Zemljič, ed. Katalonžni Zapiso Publikaciji, Maribor, Slovenia.

Faull, W. B., J. W. Hughes, M. J. Clarkson, D. Y. Downham, F. J. Manson, J. B. Merritt, R. D. Murray, W. B. Russell, J. E. Sutherst, and W. R. Ward. 1996. Epidemiology of lameness in dairy cattle: The influence of indoor and outdoor walking surfaces. Vet. Rec. 139:130-136.

Faye, B., and F. Lescourret. 1989. Environmental factors associated with lameness in dairy cattle. Prev. Vet. Med. 7:267-287.

Green, L. E., V. J. Hedges, Y. H. Schukken, R. W. Blowey, and A. J. Packington. 2002. The impact of clinical lameness on milk yield of dairy cows. J. Dairy Sci. 85:2250-2256.

Kondo, S., and J. F. Hurnik. 1990. Stabilisation of social hierarchy in dairy cows. Appl. Anim. Behav. Sci. 27:287-297.

Kossaibati, M. A., and R. J. Esslemont. 1997. The costs of production diseases in dairy herds in England. Vet. J. 154:41-51.

Livesey, C. T., and F. L. Fleming. 1984. Nutritional influences in laminitis, sole ulcer and bruised sole in Friesian cows. Vet. Rec. 114:510-512.

Livesey, C. T., T. Harrington, A. M. Johnston, S. A. May, and J. A. Metcalf. 1998. The effect of diet and housing and housing on the development of sole haemorrhages, white line haemorrhages and heel erosions in Holstein heifers. Anim. Sci. 67:9-16.

Mülling, Ch. K. W., H. H. Bragulla, S. Reese, K. D. Budras, and W. Steinberg. 1999. How structures in bovine hoof epidermis are influenced by nutritional factors. Anat. Hist. Embryol. 28:103108.

O'Callaghan, K. A., P. J. Cripps, D. Y. Downham, and R. D. Murray. 2003. Subjective and objective assessment of pain and discomfort due to lameness in dairy cattle. Anim. Welf. 12:605-610.

Peeler, E. J., M. J. Green, J. L. Fitzpatrick, K. L. Morgan, and L. E. Green. 2000. Risk factors associated with clinical mastitis in low somatic cell count British cows. J. Dairy Sci. 83:2464-2472.

Phillips, C. J. C., and I. D. Morris. 2001. The locomotion of dairy cows on floor surfaces with different frictional properties. J. Dairy Sci. 84:623-628.

Seegers, H., F. Beaudeau, C. Fourichon, and N. Bareille. 1998. Reasons for culling in French Holstein cows. Prev. Vet. Med. 36:257-271.

Singh, S. S., W. R. Ward, K. Lautenbach, and R. D. Murray. 1993a. Behaviour of lame and normal dairy-cows in cubicles and in a straw yard. Vet. Rec. 133:204-208.

Singh, S. S., W. R. Ward, K. Lautenbach, J. W. Hughes, and R. D. Murray. 1993b. Behaviour of first lactation and adult dairy cows while housed and at pasture and its relationship with sole lesions. Vet. Rec. 133:469-474.

Somers, J. G. C. J., K. Frankenna, E. N. Noordhuizen-Stassen, and J. H. M. Metz. 2005. Risk factors for digital dermatitis in dairy cows kept in cubicle houses in The Netherlands. Prev. Vet. Med. $71: 11-21$.

Sprecher, D. J., D. E. Hostetler, and J. B. Kaneene. 1997. A lameness scoring system that uses posture and gait to predict cattle reproductive performance. Theriogenology 47:1179-1187.

Stefanowska, J., D. Swierstra, C. R. Braam, and M. Hendriks. 2001. Cow behaviour on a new grooved floor in comparison with a slatted floor, taking claw health into account. Appl. Anim. Behav. Sci. 71:87-103.

Tucker, C. B., D. M. Weary, and D. Fraser. 2003. Effects of three types of free-stall surfaces on preferences and stall usage by dairy cows. J. Dairy Sci. 86:521-529.

Vermunt, J. J., and P. R. Greenough. 1996. Claw conformation of dairy heifers in two management systems. Br. Vet. J. 152:321-331.

Webster, A. J. F. 2001. Effects of housing and two forage diets on the development of claw horn lesions in dairy cows at first calving and in first lactation. Vet. J. 162:56-65.

Wechsler, B., J. Schaub, K. Friedli, and R. Hauser. 2000. Behaviour and leg injuries in dairy cows kept in cubicle systems with straw bedding or soft lying mats. Appl. Anim. Behav. Sci. 63:189-197.

Wells, S. J., L. P. Garber, and B. A. Wagner. 1999. Papillomatous digital dermatitis and associated risk factors in US dairy herds. Prev. Vet. Med. 38:11-24. 